\title{
A CONSTRUÇÃO DO CASO CLÍNICO COMO VIA DE TRANSMISSÃO DA PSICANÁLISE NAS INSTITUIÇÕES DE SAÚDE
}

\section{THE CONSTRUCTION OF THE CLINICAL CASE AS A WAY OF TRANSMISSION OF PSYCHOANALYSIS IN HEALTH INSTITUTIONS}

Eliane Costa Dias

E-mail para correspondência: delreycosta@uol.com.br

Maria Lívia T. Moretto

E-mail para correspondência: liviamoretto@usp.br

\begin{abstract}
RESUMO
Este trabalho discute o lugar da psicanálise nas instituições de saúde. Psicanálise e medicina partem de concepções de corpo, sintoma e cura radicalmente diferentes, configurando discursos e práticas clínicas necessariamente distintas. Mas, justamente por isso, a interlocução é possível e necessária. Para a maior parte dos sujeitos, a entrada no hospital constitui um momento de confronto com o real da fragilidade da condição humana e a angústia mobilizada pode gerar a demanda pela intervenção do analista. Ao psicanalista cabe a tarefa de "tocar o sujeito no doente", levando-o a se implicar com seu sintoma e seu tratamento, da melhor
\end{abstract}


maneira possível. Mas cabe também a tarefa de transmitir à equipe a dinâmica singular de cada caso e a demanda particular que ela pode configurar dentro do cotidiano do serviço de saúde. A partir de uma vinheta clínica as autoras destacam a importância da construção do caso clínico como via de transmissão do saber da psicanálise e de contribuição ao trabalho da equipe multidisciplinar.

Palavras-chave: Psicanálise; Medicina; Interdisciplinaridade; Construção de Caso Clínico.

\section{ABSTRACT}

This text discusses the role Psychoanalysis plays at health institutions. Psychoanalysis and Medicine are based on radically different concepts concerning the body, symptoms and cure, thus their discourse and clinical practices are necessarily distinct. Due to this, however, both understand interlocution is possible and necessary. Facing hospitalization, for most subjects, constitutes a confrontation with the real of the fragility inherent to the human condition, so the eruption of anguish may generate a demand for the analyst's intervention. It is the psychoanalyst's job to "touch the subject in the patient", in order to lead him to get involved in his symptom and treatment the best possible way. But also he has the task to convey to staff the unique dynamics of each case and the particular demand that it can set within the health service daily. From a clinical case relate the authors highlight the importance of building the clinical case as a mean of transmitting knowledge and effectiveness of psychoanalysis and contribution to the work of the multidisciplinary team.

Keywords: Psychoanalysis; Medicine; Interdisciplinarity; Clinical Case Construction.

\section{INTRODUÇÃO}

A discussão sobre o lugar da psicanálise nas instituições de saúde remonta ao movimento de entrada dos profissionais de saúde mental (psiquiatras, psicólogos) no espaço do hospital geral, particularmente a partir dos anos 1970, e tem mobilizado práticas e posicionamentos teóricos desde então.

O livro de Moretto (2013) O que pode um analista no hospital? enuncia com precisão conceitual os questionamentos de muitos analistas inseridos nas instituições de saúde até o momento. E conclui que psicanálise e medicina remetem a discursos distintos e a práticas clínicas necessariamente distintas também. A relação entre esses dois campos de saber é de antinomia radical. E, justamente por isso, a interlocução é possível e necessária.

$\mathrm{Na}$ conferência O lugar da psicanálise na medicina, durante sua intervenção em um colóquio de medicina a convite da pediatra e psicanalista Jeanne Aubry, 
Jacques Lacan (1966/2001) afirma que a posição da psicanálise com relação à medicina é extraterritorial.

\section{Há lugar para o saber e o fazer da psicanálise nas instituições de saúde?}

Entendemos que a aposta continua, com todos os desafios e exigências, mas esta já não é mais a questão. A presença cada vez maior e mais consistente de psicanalistas nos mais diversos contextos institucionais nos mostra que a expectativa cautelosa de Freud (1919/1980) se confirma: a psicanálise aplicada se sustenta a partir dos princípios da psicanálise pura.

A despeito de todas as formas de saber, de todos os discursos, de todas as práticas que a humanidade foi capaz de criar, o mal-estar do humano na cultura persiste e se impõe, revestindo-se das formas e roupagens tecidas a cada época.

$\mathrm{Na}$ contemporaneidade, marcada pela aliança do discurso capitalista com o discurso da ciência, assistimos a uma desordem na ordem simbólica, localizável na queda dos ideais e das referências identificatórias e num empuxo ao gozo - um imperativo de busca pela máxima e imediata satisfação. Muitas vezes, um gozo solitário, que prescinde do Outro. A lógica da globalização e do tecnicismo, ao propor a padronização e a massificação, resulta em uma "dessubjetivação" - um apagamento do sujeito, uma anulação da subjetividade e das singularidades.

Entre os efeitos dessa nova ordem social sobre a subjetividade, o corpo ganha destaque, investido como alvo privilegiado do ideal de perfeição e completude. Paradoxalmente, o corpo continua sendo via de satisfação, mas também de angústia, configurando uma das principais queixas pelas quais os sujeitos chegam aos psicanalistas - um "não saber fazer" com o corpo.

Como bem descreve Niraldo Santos (2013), no hospital a angústia no corpo nos chega por duas vias:

Em uma porta de entrada, temos os casos de urgência/emergência. Sujeitos atropelados (muitas vezes, literalmente) por um real que os convoca a perceber, diante do horror, a fragilidade da condição humana: amputação de membros, perda de uma função vital (...). Acidentes vasculares cerebrais ou tantos outros que pressionam, imediatamente, o sujeito a lidar com a castração - ou o retorno dela, fazendo deste tropeço com o real uma oportunidade única para o encontro com o psicanalista, ainda que muitas vezes o sujeito não encontre facilmente as palavras.

Mas também vemos, por outra porta do hospital, pacientes que explicitam, de modo obsceno, o gozo particular com a instalação na condição de doente. Nestes casos, o ser diabético, renal crônico, asmático, anoréxico, bulímico, é prati- 
camente indissociado de seu modo de se representar no mundo, de tão agarrados que são aos significantes que arranjaram nas contingências do destino.

Nestes casos, o psicanalista também é solicitado a intervir, pois são pacientes frequentemente poliqueixosos, não aderentes ao tratamento - ou excessivamente aderidos ao hospital e às equipes. Estes pacientes, não raramente, denunciam o fracasso das terapêuticas convencionais e confrontam os profissionais com a impotência que o gozo e a pulsão de morte sabem fazer tão bem. (paginação irregular)

Nesse ponto, retomamos uma passagem polêmica da intervenção de Lacan no referido colóquio de 1966 :

Quando o doente é enviado ao médico ou quando o aborda, não digam que ele espera pura e simplesmente a cura. Ele põe o médico à prova de tirá-lo de sua condição de doente, o que é totalmente diferente, pois isto pode implicar que ele está totalmente preso à ideia de conservá-la. Ele vem às vezes nos pedir para autenticá-lo como doente. (Lacan, 1966/2001, p. 10)

\section{Como explicar essa relação com o corpo? De que corpo se trata?}

O hospital é constituído por profissionais que têm suas ações determinadas a partir de distintos saberes e por uma ética que lhes é própria. Situada neste campo, a psicanálise precisa sustentar as especificidades de seu saber e de sua ética.

Num primeiro ponto de especificidade, verificamos que a relação psicanálise/ medicina passa pela diferença (radical) quanto às noções de corpo e sintoma. Se o corpo objeto da medicina é o corpo biológico, o organismo em funcionamento, para a psicanálise o corpo tem importância primordial na constituição e no funcionamento do psiquismo. Para além do organismo, o corpo é o "corpo erógeno":

- Corpo afetado e constituído pela ação das palavras e de suas redes simbólicas.

- Corpo-imagem - matriz identificatória para a constituição do Eu. "Eu que é antes de tudo um Eu corporal”. (Freud, 1923/1980, p. 40).

- Corpo tomado e investido pela pulsão.

- Corpo de gozo. "Um corpo é substância que se goza” (Lacan, 1966/2001, p. 11). Gozo que não se restringe ao sentido de senso comum, frequentemente associado ao prazer ou usufruto, mas como uma satisfação pulsional que está além do princípio do prazer e que, pela via da repetição, se faz excessiva, sem limites, podendo levar ao apagamento do sujeito e do desejo. "Gozo que, não atenuado pelo significante, pode tocar e atacar o corpo. O saber médico encontra aí o seu limite" (Santos, 2000, p. 296). 
Desta forma, o sintoma é a produção que nos revela a maneira singular com que cada sujeito pode fazer frente ao desafio de ter que se inserir na cultura, se posicionar diante do Outro e do desejo e se haver, ao mesmo tempo, com as exigências do real do gozo e da pulsão.

Se para a medicina a direção da cura é a extinção do sintoma, num tratamento analítico o sintoma tem que ser escutado, localizado, ressignificado.

Logo, na instituição, os conceitos fundamentais da psicanálise freudiana inconsciente, transferência, pulsão e repetição - e aqueles introduzidos a partir da releitura lacaniana - sujeito, desejo, gozo, objeto $a$ - permanecem orientando nossa clínica. Consideradas as condições e as limitações do hospital, a direção do tratamento é a mesma: tocar o sujeito no doente. E num dispositivo de fala, sob transferência, levá-lo a algum saber sobre seu sintoma e a se implicar com ele da melhor maneira possível.

A complexidade do humano na sua relação com o corpo e com o mal-estar abre espaço à psicanálise no hospital. O lugar existe e vem sendo ocupado. O desafio que se coloca, portanto, diz respeito a como sustentar esse lugar.

\section{ENTRADA NÃO É O MESMO QUE INSERÇÃO}

Como destacam Moretto e Priszkulnik (2014), a inserção do psicanalista em uma equipe de saúde não corresponde a sua entrada na instituição. O lugar do analista não diz respeito a um lugar físico ou a uma posição no organograma, mas a um lugar ético a partir do qual o analista pode operar. Um lugar que não é dado a priori e que deve ser construído a partir da práxis. A inserção seria justamente o processo de construção desse lugar.

A construção desse dispositivo de trabalho está do lado do analista e não da instituição. Depende menos das condições institucionais e muito mais do ato do psicanalista. Envolve, portanto, o desejo decidido do analista de sustentar a oferta do dispositivo clínico a partir de um saber e de uma ética próprios da psicanálise.

\section{Quais as condições e as especificidades dessa inserção?}

A inserção como processo depende, em primeiro lugar, da resposta do analista às demandas que lhe são dirigidas. Segundo Moretto e Priszkulnik (2014), o tipo de demanda dirigida ao analista decorre do tipo de relação que a equipe mantém com a subjetividade que emerge na cena médica - a dos pacientes e a sua própria. E o analista deve estar prevenido de que a demanda por um profissional com saber sobre a subjetividade não corresponde necessariamente a um desejo de querer saber sobre essa subjetividade. Com frequência, o analista é convocado a 
ocupar a posição de especialista que pode se encarregar e solucionar as dificuldades decorrentes do sofrimento psíquico dos pacientes, isentando o restante da equipe de ter que saber ou se implicar com isso.

E aqui se apresenta outra especificidade do fazer do psicanalista na instituição de saúde: o trabalho do analista articula, ao mesmo tempo, uma vertente clínica e uma vertente institucional. A vertente clínica envolve lidar propriamente com os pacientes e seu sofrimento. A vertente institucional diz respeito ao manejo das relações com as pessoas e os procedimentos que compõem a equipe. Como alerta Moretto (2006), não há inserção sem essa articulação simultânea das duas vertentes.

Essa especificidade do trabalho do analista passa pela questão da transferência - a transferência dos pacientes, sempre dupla (com o analista e com a própria instituição/medicina) e a transferência da equipe com a psicanálise. E determina as possibilidades de inserção e de ação do analista. A tal ponto que seria lícito supor que a inserção do psicanalista corresponde à instauração de uma transferência de saber com a psicanálise dentro da equipe.

A instituição de saúde é um campo de tomada de decisões (em relação à vida e ao sofrimento de pessoas) onde circulam diferentes discursos, diferentes saberes, diferentes ancoragens éticas. No entanto, regida pela lógica da ciência e do universal, prevalece na instituição o discurso do mestre que visa o ideal de uma terapêutica única e para todos. Inserido neste cenário o analista pode sustentar seu discurso e introduzir, ou melhor, reintroduzir a dimensão da subjetividade e da singularidade. E por aí, incluir novamente a dimensão do sujeito na tomada de decisões.

\section{INSERÇÃO E TRANSMISSÃO DA PSICANÁLISE}

\section{A construção do caso clínico}

$\mathrm{Na}$ atualidade, no cotidiano hospitalar vivemos cada vez mais sob a lógica da "medicina de evidências":

- Uma vertente empresarial nas instituições de saúde invocando produção e eficácia.

- Um empuxo à realização de protocolos de pesquisa que incluam instrumentos padronizados que possam quantificar os diagnósticos e as estratégias terapêuticas, que tem resultado numa supervalorização da utilização de escalas, testes e questionários.

- O imperativo das classificações diagnósticas, supostamente "ateóricas", dos manuais de classificação (CID, DSM). 
Nesta tendência de eliminar as diferenças discursivas, como sustentar o discurso da psicanálise?

O fato de Lacan ter postulado que a psicanálise trabalha na extraterritorialidade, numa posição êxtima à medicina, não isenta o psicanalista da tarefa de transmitir com precisão e clareza os efeitos da prática psicanalítica. Como aponta Santos (2003, s/p): "Expor os efeitos de nossa prática e não nos esquivarmos das tensões daí decorrentes é condição necessária à permanência nas instituições de saúde".

Transmitir o saber e o fazer da psicanálise é parte do ato analítico e de sua ética, por meio da sustentação de um método, o que não necessariamente significa responder à demanda por números, protocolos e medições.

Desde sua fundação a psicanálise se define por um método clínico em que tratamento e investigação coincidem, resultando em um conhecimento particular a cada caso. Se o material clínico é único e não pode ser padronizado, já que os efeitos não apresentam regularidade nem previsibilidade, desde Freud, a via de transmissão do saber extraído na clínica é a construção do caso.

\section{A CONSTRUÇÃO DO CASO CLÍNICO COMO VIA DE INSERÇÃO}

Existe uma maneira de falar de seus casos, própria à psicanálise?

No texto Construções em análise, Freud (1937/1980) nos lembra de que há uma segunda parte envolvida no dispositivo analítico de tratamento que é ativa e cujo papel é fundamental para o processo em curso - o analista. Se ao paciente cabe falar, associar, recordar, repetir e elaborar, ao analista cabe a tarefa de construir a verdade que resulta desse trabalho de elaboração.

Freud aproxima, embora diferenciando, a interpretação - situada como a decifração de algum elemento recalcado isolado do material do paciente (um sonho, uma associação) - e a construção que, por sua vez, visaria situar o sujeito diante de um fragmento de sua própria história, cujo sentido foi esquecido sob o efeito do recalque.

Com Lacan, entendemos que a construção do caso clínico constitui um tempo lógico diferente do ato analítico e da interpretação. É um trabalho a posterio$r i$, solitário e silencioso, em que o analista procura nomear e dar razão àquilo que está fazendo, a si mesmo e a seus pares.

Sabemos claramente o que a construção do caso não é. Não se trata de uma anamnese, de um relato das sessões do tratamento ou de um inventário da história do paciente.

Implica a possibilidade de localizar em cada caso: o sujeito, seu sintoma e a interpretação particular que ele constrói para seu mal-estar a partir dos significantes 
que lhe são importantes, da forma como ele se posiciona diante do Outro e das estratégias que dispõe para lidar com seu corpo, seu desejo e com o gozo que o atravessa.

No entanto, descrever a ordem simbólica na qual o sujeito está enredado é parte do trabalho de construção. Ela deve incluir também uma "orientação em direção ao real” (Malengreau, 2003, p. 11). Uma construção que aponte o mais singular do caso - os pontos cegos, obscuros, pontos sem sentido, que inclua a parte inusitada da experiência, a parte de "indecidível" que ela comporta.

Um método de sistematização dos significantes extraídos do discurso que o sujeito faz acerca de si, de seu mal-estar, das passagens significativas de sua história de vida. Trabalho que visa apreender a relação entre significante e gozo, ou seja, depreender dos significantes mestres que estruturam o discurso, a trajetória de um sujeito, marcada por seu encontro e desencontro com o Outro e com o real pulsional (Borges, 2010).

$\mathrm{Na}$ psicanálise de orientação lacaniana, portanto, o método clínico da construção do caso é um instrumento fundamental na formação do analista, em primeiro lugar, por configurar um modo de formalizar e de avaliar a direção de um tratamento. Mas, na medida em que só se efetiva na interlocução com os pares, esse efeito de formação é indissociável do caráter de transmissão que a construção do caso comporta.

A psicanálise configura um campo de saber com uma teoria sobre a constituição e o funcionamento do psiquismo e um método de tratamento que disponibiliza operadores que orientam a prática clínica do psicanalista na instituição. Estes operadores conceituais e técnicos podem contribuir também com a prática clínica da equipe interdisciplinar. No entanto, cabe ao psicanalista o esforço de enunciar, em seus atos e posicionamentos, em sua fala e sua escrita, a tensão entre o particular que o campo conceitual inscreve como sustentador da clínica e o singular de cada caso que se atualiza no dispositivo analítico, sob transferência. Uma transmissão que parte da impossibilidade de dizer tudo, que visa não o reconhecimento, mas o convite à interlocução e oferece ao debate o saber que recolhe.

Em relação à psicanálise aplicada, Carlo Viganó (2003, p. 49) deixa a seguinte questão:

Como fazer a construção num trabalho clínico que se desenvolve no social e não no próprio consultório, em um confronto com os outros que é veloz, cotidiano e, muitas vezes, dificultado por numerosas obrigações burocráticas?

$\mathrm{Na}$ inserção da psicanálise no campo da saúde mental, o método da construção de caso clínico tem sido apontado como um importante instrumento de pesquisa em psicanálise e como o modo pelo qual o psicanalista pode marcar a 
especificidade de seu saber e de seu fazer no trabalho em equipe e na prática institucional - extrair uma lógica singular do sintoma em cada caso. É uma maneira específica de interrogar o sofrimento psíquico revelado através dos sintomas, transmissível em sua coerência subjetiva e clínica aos demais profissionais não referidos aos fundamentos da psicanálise. "A ação do psicanalista neste trabalho 'coletivo' direciona a discussão do caso, (...) possibilitando colher das produções do sujeito os indicadores para seu tratamento e da singularidade de seus sintomas uma orientação clínica para o trabalho em equipe" (Figueiredo e Bursztyn, 2012, p. 144).

No contexto das instituições de saúde mental, na experiência de uma "prática entre vários", o método da construção do caso clínico se organiza primordialmente em torno de uma discussão clínica e diagnóstica, e tem sido proposto como uma estratégia de "conversação clínica em torno do caso", onde os diversos profissionais envolvidos com o tratamento (médico, psicólogo, terapeuta ocupacional, psicanalista ou qualquer outro) podem assumir um lugar de referência clínica e contribuir para a construção do projeto terapêutico (Borges, 2010; Figueiredo e Bursztyn, 2012; Viganó, 1999, 2003 e 2010).

Sustentamos que no hospital geral e nas instituições de saúde, o método da construção do caso clínico pode configurar, igualmente, a via para o psicanalista sustentar e transmitir a especificidade de seu modo de abordar o sofrimento do paciente e contribuir no trabalho em equipe. Sem visar propriamente uma questão diagnóstica, mas sustentando, frente aos diferentes saberes, uma lógica singular do sintoma que reintroduza a dimensão do sujeito na compreensão do caso e na tomada de decisões.

$\mathrm{Na}$ argumentação dessa aposta, recorreremos a uma vinheta clínica ${ }^{1}$.

\section{MARIO E O VEGETAL}

O Serviço de Psicologia de um hospital recebe o seguinte pedido, proveniente da clínica cirúrgica:

Mario, 43 anos, portador de neoplasia de reto + colostomia. Apresentando quadro intenso de náuseas, vômitos e dores estomacais, sem aparente causa clínica. Está negativista, depressivo, com difícil contato. Solicito avaliação e conduta.

1 Trata-se de uma vinheta clínica, recortada de um caso encerrado, tomada como ilustração da discussão proposta. Para tanto, o paciente recebeu um nome fictício e foram omitidos todos os dados que pudessem levar a alguma identificação. 
$\mathrm{Na}$ enfermaria, em contato com a equipe a psicóloga/psicanalista é informada que o paciente era acompanhado nesta clínica desde quando foi internado pela primeira vez para remover um tumor no intestino. No momento, fora internado para uma cirurgia renal exploratória (por suspeita de possível recidiva de câncer). A cirurgia transcorreu bem e o pós-operatório foi excelente. Há mais ou menos seis dias, no entanto, vinha apresentando quadro de vômitos e dores abdominais. A ausência de achados clínicos leva a equipe médica a enunciar a hipótese de "algo emocional, somatização". Hipótese que ao ser comunicada ao paciente, para surpresa dos profissionais, o deixa ainda mais nervoso e queixoso.

A demanda da equipe é clara: "Quem sabe uma psicóloga saiba como fazê-lo entender e mudar de atitude".

Desde a primeira entrevista, o paciente deixa claro que não aceita a hipótese de "somatização" sugerida pela equipe médica. Embora se mantendo resistente e desconfiado se dispõe a falar e reconstitui sua história.

Self-made man é o significante com que ele se representa. Um homem batalhador, ativo e independente, bem-sucedido por seus méritos e esforços. Uma vida conduzida com rigor, controle e racionalidade, só surpreendida pelo diagnóstico de câncer. Conta que começou a sentir fortes dores no abdome. Procurou uma clínica onde fez vários exames e quando retornou para saber os resultados foi informado pelo médico de que se tratava de câncer.

Disseram de cara que era câncer e que se não fizesse cirurgia teria apenas uns meses de vida. Saí de lá em choque. Por conselho de amigos, decidi procurar um especialista e fui encaminhado para a equipe deste hospital. Disseram que eram os melhores, todos catedráticos da USP. Quando conversei com o dr. X, ele confirmou o diagnóstico e me tranquilizou dizendo que, com certeza sairia bem da cirurgia e após o tratamento de quimioterapia voltaria a ter vida normal. Em três dias eu já estava internado e sendo operado. Não deu nem tempo de pensar. Sabe o que aconteceu? Quando acordei estava na UTI e percebi que estava assim (aponta para a bolsa de colostomia). Disseram que a cirurgia havia sido pior que imaginavam e a colostomia foi necessária e seria irreversível ... Me senti um mutilado ... Como é possível ter vida normal desse jeito? [grifos nossos]

Questionado sobre os sintomas gástricos, Mario refere que assim que começou a receber alimentação sólida, passou a ter vômitos e dores que foram piorando cada vez mais:

Da outra vez, disseram que eu ia sair bem e saí sem intestino. Fico pensando que desta vez, vou sair sem estômago. Eu não aceito. Para ficar assim, 
prefiro morrer. Não quero ficar como um vegetal . . . Isso não seria vida! E aí, dá para dizer que pensar desta forma é estar louco? Inventando dores que não existem?

$\mathrm{Na}$ escuta de Mario, "saber" e "vegetal” são significantes primordiais. O saber, o conhecimento, foi o objeto de valor (fálico) que ancorou sua identidade e o moveu em todos os seus investimentos na vida. Mais que isso, era a estratégia subjetiva para se posicionar diante do Outro. A transferência com a medicina e com a equipe fora estabelecida sob este significante. A defesa vacila quando a certeza do saber falha e ele se vê confrontado com um real que se abre no corpo. $\mathrm{Na}$ internação atual, a angústia se potencializava na medida em que se via desabonado pela equipe em seu próprio saber.

Nas entrevistas seguintes, o significante "vegetal" aponta para seu fantasma. Mario recorda que seu pai falecera com câncer, tendo sofrido muito no tratamento. "Conseguiram remover o tumor, mas ele não saiu mais da cama. Cuidei dele todo o tempo, mas nunca aceitei aquela situação . . . ver meu pai como um vegetal, passivo, sem vontade própria.” [grifo nosso]

Estes pontos foram discutidos com a equipe e o significante "somatização" pôde ser questionado e ressignificado. O oncologista responsável pôde abordar o paciente de outra posição, legitimando seu mal-estar e informando com clareza e objetividade as hipóteses, as condutas e os resultados. A mudança de posicionamento favoreceu o restabelecimento da transferência de saber e a reorganização da defesa. Mario, ainda com dores, retornou ao acompanhamento ambulatorial e manteve sessões periódicas com a analista por cerca de quatro meses, "afinal, falar com uma especialista era uma forma de pensar melhor."

Pouco mais de um ano após essa internação, Mario volta ao hospital com um novo quadro de dores abdominais intensas. Os exames indicavam inúmeros tumores no intestino, desta vez, sem perspectiva de intervenção cirúrgica. Nas discussões com a equipe, se instaura a polêmica sobre o quanto e como informar o paciente. A analista recoloca a importância de o paciente ter preservada a posição de sujeito capaz de saber e opinar. Informado sobre a gravidade do quadro e o caráter paliativo do tratamento, Mario opta por receber medicação ambulatorial. O tratamento analítico acontece durante as aplicações semanais de medicação e constituem um espaço de fala, por vezes no silêncio, em que ele, sem nunca falar sobre a morte organiza e reorganiza suas estratégias para lidar com o real da debilitação física e da finitude.

Em dado momento, numa nova internação, o pedido do paciente por sedação impacta e divide a equipe. Em uma consulta conjunta com o oncologista e a analista Mario deixa claro que chegou ao seu limite, recusa a transferência para 
uma unidade de cuidados paliativos e pede apenas um breve retorno para a sua casa para as "últimas providências".

Em uma reunião convocada de urgência, diante de uma equipe tomada pela ânsia de "fazer o bem", disponibilizando todos os recursos tecnológicos disponíveis, a fala do chefe da equipe interdisciplinar funciona como ponto de basta: "a quem interessa prolongar esse sofrimento?”. Essa intervenção reorienta a equipe que assume a condução da sedação, acolhendo os familiares do paciente pelo período em que permaneceram as funções vitais.

Retornando à questão de Viganó (2003) citada anteriormente, no cotidiano, por vezes avassalador, das instituições de saúde, como sustentar a construção e a afirmação da subjetividade singular de cada caso, de cada sujeito?

Acreditamos que a resposta passa pelo desejo do analista. O pivô da construção do caso clínico e de sua transmissão não é somente a presença do analista, mas o desejo do analista como desejo de fazer advir o sujeito, de fazer advir a "pura diferença”, como o define Lacan (1964/1988). Este desejo decidido pode sustentar a prática clínica e, potencialmente, inspirar a constituição de uma transferência de trabalho com a psicanálise no interior da equipe de saúde.

Fica-nos, portanto, o desafio de verificar se nossa prática clínica institucional é capaz de levar nossos pacientes a um "saber haver-se" com o corpo em sua relação com a vida e com o desejo. E se o que é causa de desejo em cada um de nós é capaz de nos levar a um "saber-fazer" e à coragem de sustentar, em atos, o discurso da psicanálise.

\section{REFERÊNCIAS}

Borges, A. (2010). Elementos mínimos para a construção do caso clínico na prática entre vários. CliniCAPS, 4(11).

Figueiredo, A. C., \& Bursztyn, D. C. (2012). O tratamento do sintoma e a construção do caso clínico na prática coletiva em saúde mental. Tempo Psicanalítico, 44(1), 131-145.

Freud, S. (1919/1980). Linhas de progresso na terapia psicanalítica. ESB das Obras Completas de Sigmund Freud, vol. XVII. Rio de Janeiro, RJ: Imago.

Freud, S. (1923/1980). O Ego e o Id. ESB das Obras Completas de Sigmund Freud, v. XIX. Rio de Janeiro, RJ: Imago.

Freud, S. (1937/1980). Construções em análise. ESB das Obras Completas de Sigmund Freud, vol. XXIII. Rio de Janeiro, RJ: Imago.

Lacan, J. (1964/1988). O Seminário. Livro 11: Os quatro conceitos fundamentais da psicanálise. 1a ed. Rio de Janeiro, RJ: Zahar.

Lacan, J. (1966/2001). O lugar da psicanálise na medicina. Opção lacaniana, 32, 8-14.

Malengreau, P. (2003). Nota sobre a construção do caso. Almanaque de psicanálise e saúde mental, ano 6, (9), 11-15. 
Moretto, M. L. T. (2013). O que pode um analista no hospital?. 4. ed. São Paulo, SP: Casa do Psicólogo.

Moretto, M. L. T. (2006). O psicanalista num programa de transplante de fígado: a experiência do "outro em si". Tese de doutorado. Instituto de Psicologia, Universidade de São Paulo, São Paulo, SP.

Moretto, M. L. T. \& Priszkulnik, L. (2014). Sobre a inserção e o lugar do psicanalista na equipe de saúde. Tempo Psicanalítico, v. 46.2, 287-298.

Santos, F. J. B. (2000). Do corpo médico ao corpo da psicanálise. O corpo da psicanálise. Escola Letra Freudiana, ano XVII, (27), 293-299.

Santos, N. O. (2003, novembro). Brasil. Psicanálise. Medicina. Extraterritorial: Mais, ainda. Carta de São Paulo Online, n. 5, nova série, ano III, paginação irregular.

Viganó, C. (1999, setembro). A construção do caso clínico em saúde mental. Curinga: psicanálise e saúde mental. Escola Brasileira de Psicanálise, seção Minas Gerais, (13), 50-59.

Viganó, C. (2003, novembro). A construção do caso. Almanaque de psicanálise e saúde mental, ano 6, (9), 47-50.

Viganó, C. (2010, março). A construção do caso clínico. Opção Lacaniana online nova série, ano 1, (1), 1-9. 
